${ }^{1}$ Сергій Олексійович Оберемок

${ }^{2}$ Серхій Васильович Поліщук (канд. військ. наук)

${ }^{1}$ Кіровоградська льотна академія Національного авіаційного університету, Кропивницький

${ }^{2}$ Національний університет оборони Украйни імені Івана Черняховського, Київ, Украйна

\title{
МАТЕМАТИЧНА МОДЕЛЬ ПРОЦЕСУ ПЕРЕДАЧІ ДАНИХ В РЕЖИМІ ВИЯВЛЕННЯ ПОМИЛОК ОТРИМУВАЧЕМ 3 УРАХУВАННЯМ ВІДМОВ НА ВУЗЛАХ КОММУТАЦІЇ В МЕРЕЖАХ АСУ ПОВІТРЯНИМ РУХОМ
}

\begin{abstract}
При передачі інформації в сучасних мережах автоматизованих систем управління повітряним рухом використовують різноманітні методи управління обміном даними, щзо обумовлено необхідністю забезпечення часу доставки та допустимого значення еквівалентної ймовірності помилки. При ијьому для гарантованої доставки повідомлень здійснюється контроль достовірності переданих даних, який реалізується за рахунок застосування завадостійкого кодування в режсиах виявлення або виправлення помилок з перевіркою на кожному з проміжних вузлів комутації або безпосередньо одержувачем. Таким чином, для дослідження ймовірнісно-часових характеристик методів управління обміном даними в мережах обміну даними необхідно провести аналіз прочесу передачі пакетів в зазначених режимах із урахуванням впливу проміжних вузлів комутації. У статті описана математична модель, яка дозволяє дослідити основні ймовірнісно-часові характеристики процесу передачі даних в мережах автоматизованих систем управління повітряним рухом в режимі виявлення помилок із урахуванням додаткових потоків інформації від інших джерел та ймовірних відмов на вузлахкомутації.

Ключові слова: мережі обміну даними, передача даних, пакети даних, ймовірнісно-часові характеристики, вузол комутації, виправлення помилок, ймовірнісно-часовий граф.
\end{abstract}

\section{ВстуII}

Під час передачі інформації в сучасних мережах застосовують різні методи управління обміном даними, що обумовлено необхідністю забезпечення заданого часу доставки i допустимого значення еквівалентної ймовірності помилки. Аналіз процесу передачі пакетів вимагає врахування впливу проміжних вузлів комутації.

Виходячи 3 розподіленої топології існуючих мереж обміну даними (МОД) пакети в більшості випадків передаються через проміжні вузли комутації (ВК). Для протоколів гарантованої доставки здійснюється контроль достовірності переданих даних, який реалізується за рахунок застосування завадостійкого кодування в режимах виявлення або виправлення помилок з перевіркою на кожному з проміжних ВК або безпосередньо одержувачем. Втрачені i спотворені пакети відновлюються шляхом повторних передач.

Постановка проблеми. Для дослідження ймовірнісно-часових характеристик методів управління обміном даними в МОД необхідно провести аналіз процесу передачі пакетів в зазначених режимах із урахуванням впливу проміжних ВК. При цьому в загальному випадку слід враховувати як наявність декількох потоків даних від інших джерел, так і можливість виникнення відмов в обслуговуванні на кожному 3 вузлів комутації.

Аналіз остатніх досліджень і публікацій. В [1] описана модель простої біт-орієнтованої процедури передачі даних 3 квітіруваням для однієї ланки передачі без урахування додаткових потоків на ВК.

В [2] була показана можливість втрати пакетів у ВК в умовах пікових навантажень, а також приведено формулу орієнтованого розрахунку розміру буферів для заданих параметрів.

В [3] розроблена математична модель процесу комутації в пристроях 3 повнозв'язною топологією.

В [4] приведена модель, яка дозволяє дослідити основні ймовірнісно-часові характеристики процесів передачі даних в МОД для випадку застосування завадозахищеного коду в режимі виявлення помилок 3 перевіркою пакетів отримувачем при передачі даних через проміжні ВК. В моделі було враховані додаткові потоки інформації на ВК, але не було враховано здатність відмов в обслуговуванні.

Метою статті $\epsilon$ розроблення математичної моделі, яка дозволить дослідити основні ймовірнісно-часові характеристики процесу передачі даних в режимі виявлення помилок отримувачем 3 урахуванням можливих відмов на вузлі комутації мережі АСУ повітряним рухом.

\section{Виклад основного матеріалу дослідження}

Нехай джерело видає повідомлення довжиною М розрядів, яке розбивається на пакети 3 інформаційною частиною $\mathrm{m}$ розрядів. Тоді кількість сформованих 3 повідомлення пакетів дорівнює $\mathrm{M} / \mathrm{m}$. До кожного пакету додається $\mathrm{k}_{\text {сл }}$ службових розрядів i $r$ перевірочних. Загальнадовжина сформованого пакета дорівнює 
$\mathrm{n}=\mathrm{m}+\mathrm{k}_{\mathrm{cлл}}+\mathrm{r}$.

При відсутності повторень кожен пакет буде доставлений за час $\mathrm{T}_{\text {п }}=\mathrm{n} / \mathrm{B}$.

Тривалість тайм-ауту пропорційна часу доставки пакета: $\mathrm{T}_{\mathrm{Ta}}=\eta \mathrm{T}_{\text {п }}$.

Використаємо наступні позначення ймовірностей:

$\mathrm{P}_{\text {пр }}-$ правильного прийому пакета;

$\mathrm{P}_{\text {вп }}-$ виявлення помилки в пакеті;

$\mathrm{P}_{\text {нвп }}-$ не виявлення помилки в пакеті;

$\mathrm{P}_{\text {внг }}-$ виникнення помилки в пакеті $\left(\mathrm{P}_{\mathrm{B \Pi}}=\mathrm{P}_{\text {вп }}+\mathrm{P}_{\text {нвп }}\right)$;

$\mathrm{P}_{\text {втр}}-$ втрати пакета.

Причому $\mathrm{P}_{\text {вн }}+\mathrm{P}_{\text {вп }}+\mathrm{P}_{\text {нв }}+\mathrm{P}_{\text {втр }}=1$.

Розглянемо передачу повідомлень через проміжні ВК з перевіркою пакетів одержувачем і відновленням втрачених i спотворених (3 виявленою помилкою) пакетів за допомогою повторних передач.

Припустимо, що на кожному з ВК у разі переповнення вхідних буферів можлива відмова в обслуговуванні, тобто втрата пакета. Позначимо цю ймовірність як $\mathrm{P}_{\text {втр }}^{\text {вк }}$ У загальному випадку вона буде залежати від архітектури комутатора, який застосовується, методу комутації, довжини вхідних і вихідних буферів, а також параметрів трафіку.

Пакети, що проходять через проміжні ВК, кількість яких позначимо через $\beta$, затримуються на кожному з них на час $\Delta \mathrm{t}$, або можуть бути втрачені через відмову в обслуговуванні. Сумарна затримка повідомлення не залежить від числа пакетів в ньому і дорівнює $\beta \Delta \mathrm{t}$.

Час очікування пакета в черзі на обслуговування на проміжних ВК визначається згідно [5].

Для аналізу ймовірнісно-часових процесів мереж i систем обміну даними широко застосовують теорію масового обслуговування [6].
Але цей математичний апарат не дозволяє в повній мірі враховувати особливості протоколів інформаційного обміну, зокрема - процедури повторної передачі спотворених пакетів.

Наведеним поданням процесу передачі даних найбільш відповідає математичний апарат вироблення функцій [8]. При його використанні будують ймовірнісно-часовий граф (ЙЧГ), що описує аналізований процес. Кожна дуга ЙЧГ характеризується ймовірністю іiі вибору і часом переходу. При цьому вид функції дуги повинен бути таким, щоб при знаходженні творів функцій ймовірності множилися, а час підсумовувався. [7].

Узагальнена функція відповідного ЙЧГ, є сумою функцій всіх шляхів, що з'єднують початкову і кінцеві вершини графа.

Для iï отримання вихідний ЙЧГ піддають послідовним еквівалентним перетворенням, що проводяться за певними правилами. Еквівалентні перетворення, зазвичай, проводять до тих пір, поки не буде отримана функція, що характеризує перехід 3 початкового в кінцевий стан. 3 отриманої функції знаходять середній час виконання досліджуваного процесу і його дисперсію:

$$
\begin{gathered}
\mathrm{T}_{\mathrm{c}}=\left.\frac{\mathrm{F}(\mathrm{Z})}{\mathrm{dZ}}\right|_{\mathrm{Z}=1}, \\
\mathrm{D}_{\mathrm{T}_{\mathrm{c}}}=\left.\frac{\mathrm{d}^{2} \mathrm{~F}(\mathrm{Z})}{\mathrm{dZ}}\right|_{\mathrm{Z}=1}+\left.\frac{\mathrm{dF}(\mathrm{Z})}{\mathrm{dZ}}\right|_{\mathrm{Z}=1}-\left(\left.\frac{\mathrm{dF}(\mathrm{Z})}{\mathrm{dZ}}\right|_{\mathrm{Z}=1}\right)^{2} .
\end{gathered}
$$

Оскільки в розглянутому методі дуги ЙЧГ характеризуються ймовірністю переходу, необхідно знати вирази для їх визначення. Тому слід визначити математичні моделі помилок в комп'ютерних мережах, які будуть використані при аналізі ймовірнісно-часових характеристик.

На рис.1 наведено ЙЧГ, що характеризує процес передачі пакетів з урахуванням повторних передач.

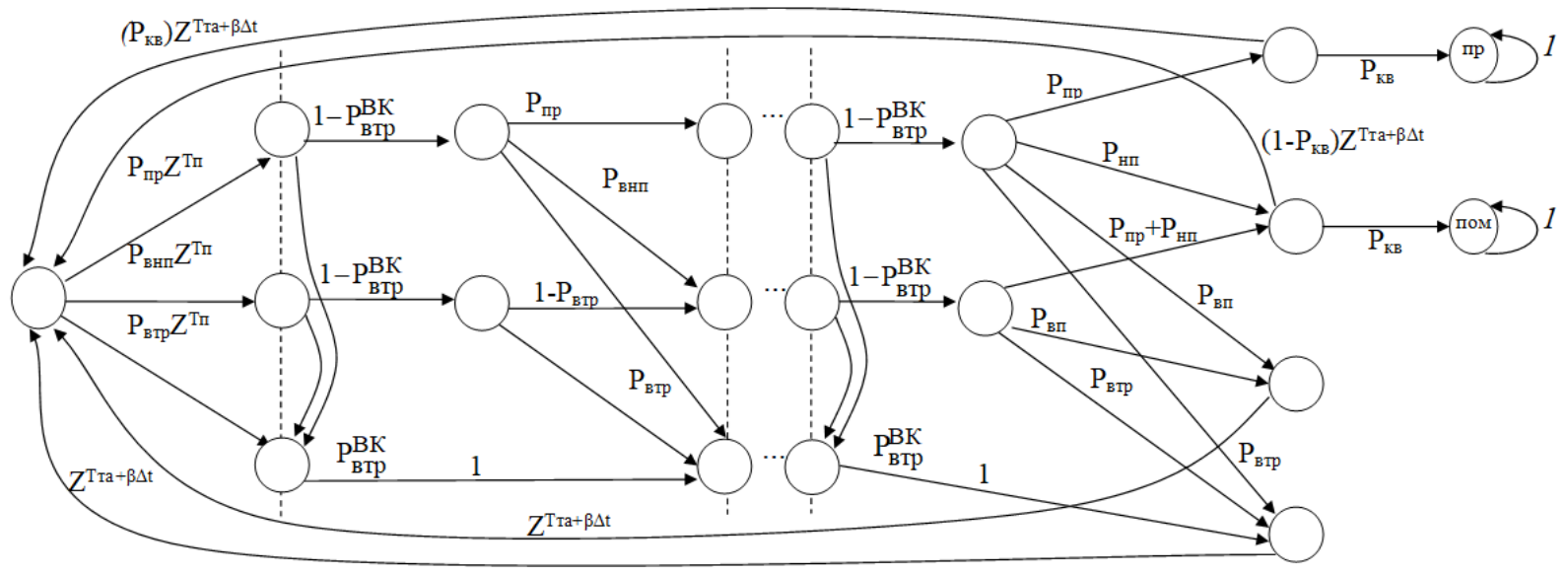

Рис.1. Вихідний ймовірнісно-часовий граф процесу передачі пакетів

Після еквівалентних перетворень отримаємо граф (рис. 2), дуги якого описуються виразами:

$$
\begin{gathered}
\mathrm{f}_{\ni 1}=\mathrm{P}_{\text {пр }}^{\beta+1}\left(1-\mathrm{P}_{\text {втр }}^{\text {ВК }}\right)^{\beta} \mathrm{P}_{\text {кв }} \mathrm{Z}^{\text {Тп }} \\
\mathrm{f}_{\ni 2}=\left(\mathrm{P}_{\text {вп }}+\mathrm{P}_{\text {пр }}\right)^{\beta}\left(1-\mathrm{P}_{\text {втр }}^{\text {ВК }}\right)^{\beta} \mathrm{P}_{\text {нвп }} \mathrm{P}_{\text {кв }} \mathrm{Z}^{\text {Тп }}
\end{gathered}
$$

$$
\begin{gathered}
f_{э 3}=\left[1-\left(P_{\text {вп }}+P_{\text {пр }}\right) \beta\left(1-P_{\text {втр }}^{\text {BК }}\right)^{\beta}\left(P_{\text {пр }}+P_{\text {нвп }}\right) P_{\text {кв }}\right] \\
Z^{\text {Tп }+\beta \Delta t+\text { Tma }}
\end{gathered}
$$




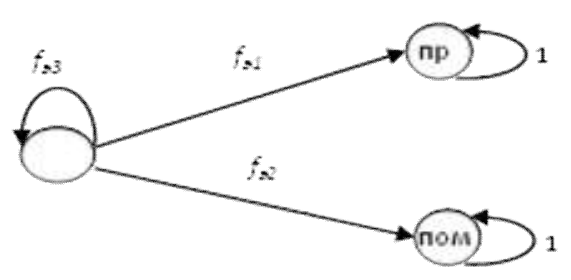

Рис.2. Еквівалентний ймовірнісно-часовий граф

Імовірність помилки:

$$
\begin{aligned}
& P_{\text {(пом } F}=\left.\frac{\mathrm{f}_{э 2}}{1-\mathrm{f}_{\ni 3}}\right|_{\mathrm{z}=1} \\
& =\frac{\left(\mathrm{P}_{\text {вп }}+\mathrm{P}_{\text {пр }}\right)^{\beta}\left(1-\mathrm{P}_{\text {втр }}^{\text {ВК }}\right)^{\beta} \mathrm{P}_{\text {нвг }} \mathrm{P}_{\text {кв }}}{\left(1-\left[1-\left(\mathrm{P}_{\text {вп }}+\mathrm{P}_{\text {пр }}\right)^{\beta}\left(1-\mathrm{P}_{\text {втр }}^{\text {BK }}\right)^{\beta}\left(\mathrm{P}_{\text {пр }}+\mathrm{P}_{\text {нвп }}\right) P_{\text {кв }}\right]\right)}= \\
& =\frac{\mathrm{P}_{\text {нвп }}}{\left(\mathrm{P}_{\text {пр }}+\mathrm{P}_{\text {нІ }}\right)}=\frac{\mathrm{P}_{\text {нвп }}}{\left(1-\mathrm{P}_{\text {вП }}-\mathrm{P}_{\text {вт }}\right)} \text {. }
\end{aligned}
$$

Узагальнена функція буде мати вигляд:

$$
\begin{aligned}
& F(Z)=\frac{f_{31}+f_{32}}{1-f_{33}}= \\
& =\frac{\left[\left(\mathrm{P}_{\text {пр }}^{\beta+1}+\left(\mathrm{P}_{\text {вп }}+\mathrm{P}_{\text {пр }}\right)^{\beta} \mathrm{P}_{\text {нвп }}\right) \cdot\left(1-\mathrm{P}_{\text {втр }}^{\text {BК }}\right)^{\beta} \mathrm{P}_{\text {кв }} Z^{\text {Tп }}\right]}{1-\left[1-\left(\mathrm{P}_{\text {вп }}+\mathrm{P}_{\text {пр }}\right)^{\beta}\left(1-\mathrm{P}_{\text {втр }}^{\text {BK }}\right)^{\beta}\left(\mathrm{P}_{\text {пр }}+\mathrm{P}_{\text {нвп }}\right) \mathrm{P}_{\text {кв }}\right]} \cdot Z \\
& \mathrm{C}=\left(\mathrm{P}_{\text {пр }}^{\beta+1}+\left(\mathrm{P}_{\text {вп }}+\mathrm{P}_{\text {пр }}\right)^{\beta} \mathrm{P}_{\text {нвп }}\right) \cdot\left(1-\mathrm{P}_{\text {втр }}^{\mathrm{BK}}\right)^{\beta} \mathrm{P}_{\text {кв }} \text {, } \\
& \mathrm{D}=1-\left(\mathrm{P}_{\text {вп }}+\mathrm{P}_{\text {пр }}\right)^{\beta}\left(1-\mathrm{P}_{\text {втр }}^{\text {BК }}\right)^{\beta}\left(\mathrm{P}_{\text {пр }}+\mathrm{P}_{\text {нвп }}\right) \mathrm{P}_{\text {кв }} \text {. }
\end{aligned}
$$

Тоді, виходячи з (7) i (8), середній час доставки одного пакета:

$$
\begin{gathered}
\mathrm{T}_{\mathrm{cl}}=\left.\frac{\mathrm{d}}{\mathrm{dZ}}\left(\frac{\mathrm{C} \cdot \mathrm{Z}^{\text {Тп }}}{1-\mathrm{D} \cdot \mathrm{Z}^{\text {Тп }+\beta \Delta t+\mathrm{T}_{\mathrm{TT}}}}\right)\right|_{\mathrm{Z}=1}= \\
=\frac{\mathrm{C}}{(\mathrm{D}-1)^{2}}\left[\mathrm{~T}_{\text {пा }}+\mathrm{D} \cdot\left(\mathrm{T}_{\mathrm{Ta}}+\beta \Delta \mathrm{t}\right)\right] .
\end{gathered}
$$

Прийнявши $\mathrm{PKB}=1$ і $\mathrm{P}_{\text {втр }}=0$ на основі виразу отримаємо:

$$
\begin{aligned}
& \mathrm{C}=\left(\mathrm{P}_{\text {пр }}^{\beta+1}+\mathrm{P}_{\text {нвп }}\right) \cdot\left(1-\mathrm{P}_{\text {втр }}^{\text {BК }}\right)^{\beta}, \\
& \mathrm{D}=1-\left(1-\mathrm{P}_{\text {вп }}\right) \cdot\left(1-\mathrm{P}_{\text {втр }}^{\text {BK }}\right)^{\beta}, \\
& \mathrm{T}_{\mathrm{cl}}=\frac{\mathrm{P}_{\text {пр }}^{\beta+1}+\mathrm{P}_{\text {нвп }}}{\left(1-\mathrm{P}_{\text {вп }}\right)^{2}\left(1-\mathrm{P}_{\mathrm{BT}}^{\mathrm{BK}}\right)^{\beta}} \times
\end{aligned}
$$

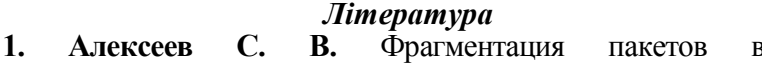
биториентированой процедуре передачи данных с квитированием /С. В. Алексеев, А. М. Прозоров, Д. А. Коваленко // Радіолектронні і комп'ютерні системи. 2005. - № 2(10). - С. 11-18. 2. Оберемок С. Модель обробки пакетів в комутаційних вузлах 3 повнозв'язною топологією мережі АСУ повітряним рухом / С.О.Оберемок. //Системи управління навігації та зв'язок. - 2018. - № 1(47) - С. 28-31. 3. Оберемок С. О. Математична модель процесу комутації в засобах з повнозв'язною топологією в мережах АСУ повітряним рухом / С. О. Оберемок. // Системи управління навігації та зв'язок. - 2018. - № 2(48). - С. 30-34. 4. Алексеев С. В. Математическая модель процесса передачи данных через промежуточные центры коммутации сообщений для случая применения помехоустойчивого кода в режиме обнаружения ошибок с
}

$$
\times\left[\mathrm{T}_{\text {пा }}+\left(1-\left(1-\mathrm{P}_{\text {вп }}\right)\left(1-\mathrm{P}_{\text {втр }}^{\mathrm{BK}}\right)^{\beta}\right) \cdot\left(\mathrm{T}_{\mathrm{Ta}}+\beta \Delta \mathrm{t}\right)\right] .
$$

Отже, справедливий вираз:

$$
\begin{gathered}
\mathrm{T}_{\mathrm{cl}}=\frac{\mathrm{P}_{\text {пр }}^{\beta+1}+\mathrm{P}_{\text {нвп }}}{\left(1-\mathrm{P}_{\text {вп }}\right)^{2}\left(1-\mathrm{P}_{\text {ВТр }}^{\mathrm{BK}}\right)^{\beta}} \times \\
\times\left[\frac{\mathrm{n}}{\mathrm{B}}+\left(1-\left(1-\mathrm{P}_{\text {вп }}\right)\left(1-\mathrm{P}_{\text {Втр }}^{\mathrm{BK}}\right){ }^{\beta}\right)\left(\eta \frac{\mathrm{n}}{\mathrm{B}}+\beta\left[\frac{\mathrm{B}}{\mathrm{n}}-\lambda\right]^{-1}\right)\right] .
\end{gathered}
$$

Оскільки всього пакетів $\mathrm{M} / \mathrm{m}$, середній час доставки повідомлення 3 урахуванням часу очікування на проміжних ВК дорівнює:

$$
\begin{gathered}
\mathrm{T}_{\text {д.с }}=\frac{\mathrm{M}}{\mathrm{m}}\left[\frac{\mathrm{P}_{\text {пр }}^{\beta+1}+\mathrm{P}_{\text {нвп }}}{\left(1-\mathrm{P}_{\text {вп }}\right)^{2}\left(1-\mathrm{P}_{\text {втр }}^{\mathrm{BK}}\right)^{\beta}} \times\right. \\
\left.\times\left[\frac{\mathrm{n}}{\mathrm{B}}+\left(1-\left(1-\mathrm{P}_{\text {вп }}\right)\left(1-\mathrm{P}_{\text {втр }}^{\mathrm{BK}}\right)^{\beta}\right)\left(\eta \frac{\mathrm{n}}{\mathrm{B}}+\beta\left[\frac{\mathrm{B}}{\mathrm{n}}-\lambda\right]^{-1}\right)\right]\right]+ \\
\beta\left[\frac{\mathrm{B}}{\mathrm{n}}-\lambda\right]^{-1} .
\end{gathered}
$$

Якщо час оцінювати за кількістю переданих посилок (при швидкості модуляції $\mathrm{B}=1$ біт/c) i не враховувати впливу інших потоків інформації, отримаємо відносний середній час доставки:

$$
\begin{gathered}
\mathrm{T}_{\text {д }}=\frac{\mathrm{M}}{\mathrm{m}}\left[\frac{\mathrm{P}_{\text {пр }}^{\beta+1}+\mathrm{P}_{\text {нвп }}}{\left(1-\mathrm{P}_{\text {вп }}\right)^{2}\left(1-\mathrm{P}_{\text {втр }}^{\mathrm{BK}}\right)^{\beta}} \times\right. \\
\left.\times\left[\mathrm{n}+\left(1-\left(1-\mathrm{P}_{\text {вп }}\right)\left(1-\mathrm{P}_{\text {втр }}^{\text {BK }}\right)^{\beta}\right)(\eta \mathrm{n}+\beta \mathrm{n})\right]\right]+\beta \mathrm{n} .
\end{gathered}
$$

Імовірність помилки 3 прийнятими допущеннями:

$$
\mathrm{P}_{(\text {п) }}=\mathrm{P}_{\text {нвп }} /\left[1-\mathrm{P}_{\text {вп }}\right] \text {. }
$$

\section{Висновки й перспективи подальших досліджень}

Таким чином, розроблена математична модель дозволяе проаналізувати основні ймовірнісночасові характеристики процесів передачі даних в режимі виявлення помилок отримувачем 3 урахуванням додаткових потоків та можливих відмов на вузлах комутації в мережах АСУ повітряним рухом.

проверкой пакетов получателем / С. В. Алексеев //Збірник наукових праць ХУПС, 2010. - Вип. 3(25). - С. 123-125. 5. Бертсекас Д. Сети передачи данных / Д. Бертсекас, Р. Галлагер / пер. с англ. - М.: Мир, 1989. - 544 с. 6. Зайченко Ю. П., Гонта Ю. В. Структурная оптимизация сетей ЭВМ. - К.: Техника, 2006. - 168 с.

7. Березко М. П. Математические модели исследования алгоритмов маршрутизации в сетях передачи данных / M. П. Березко, В. М. Вишневский, Е. В. Левнер, Е. В. Федотов] // Информационные процессы. - 2011. - Т.1, № 2. - С. 103 125. 8. Харитонов О. А. Качество обслуживания и эффективное использование ресурсов в мультисервисных сетях // Вестник связи. - 2014. - № 12. - С. 48-55. 9. Поповский В. В. Математическое моделирование сложных систем / В. В. Поповский. - Л.: Военная академия связи, 1990. - 156 с. 10. Шварцман В. О. Качество услуг сетей следующего поколения / В. О. Шварцман // 


\title{
Электросвязь. - $2016 . \quad$ - № 3.-С. 26-31. \\ МАТЕМАТИЧЕСКАЯ МОДЕЛЬ ПЕРЕДАЧИ ДАННЫХ В РЕЖИМЕ ОБНАРУЖЕНИЯ ОШИБОК ПОЛУЧАТЕЛЯ С УЧЕТОМ ОТКАЗОВ НА УЗЛАХ КОММУТАЦИИ В СЕТЯХ АВТОМАТИЗИРОВАНЫХ СИСТЕМ УПРАВЛЕНИЯ ВОЗДУШНЫМ ДВИЖЕНИЕМ
}

\author{
${ }^{1}$ Сергей Алексеевич Оберемок \\ ${ }^{2}$ Сергей Васильевич Полищук (кандидат военных наук) \\ ${ }^{1}$ Кировоградськая льотная академия Национального авиационного университета, Крапивницкий \\ ${ }^{2}$ Национальный университет обороны Украины имени Ивана Черняховського, Киев, Украина
}

\begin{abstract}
При передаче информации в современных сетях АСУ воздушным движением используют различные методы управления обменом данными, что обусловлено необходимостью обеспечения времени доставки и допустимого значения эквивалентной вероятности ошибки. Для гарантированной доставки сообщений осуществляется контроль достоверности передаваемых данных, который реализуется за сет применения помехоустойчивого кодирования в режимах обнаружения или исправления ошибок с проверкой на каждом из промежуточных узлов коммутации или непосредственно получателем. В статье описана математическая модель передачи данных в режиме обнаружения ошибок получателя, которая позволяет исследовать основнье вероятностно-временнье характеристики прочесса передачи данных в сетях АСУ воздушным движением в режиме обнаружения ошибок с учетом дополнительных потоков информачии от других источников и возможных отказов на узлах коммутации.
\end{abstract}

Ключевые слова: сети обмена данными, передача данных, пакеты данных, вероятностновременные характеристики, узел коммутации, исправление ошибок, вероятностно-временной граф.

\section{MATHEMATICAL MODEL OF TRANSMISSION OF DATA IN THE MODE OF DETECTING THE ERRORS OF THE RECIPIENT WITH ACCOUNT OF FAILURES AT THE COMMUTATION NETWORKS IN NETWORKS OF AUTOMATED AIR TRAFFIC CONTROL SYSTEMS}

\author{
${ }^{1}$ SerhiiA.Oberemok \\ ${ }^{2}$ Serhii V. Polishchuk (Candidate of Military Sciences)
}

\author{
${ }^{1}$ Kirovograd AircraftAcademyoftheNationalAviationUniversity, Krapivnitsky, Ukraine \\ ${ }^{2}$ National Defence University of Ukraine named after Ivan Cherniakhovsky, Kyiv, Ukraine
}

When transmitting information in modern networks of automated air traffic control systems, various methods of data exchange control are used, which is caused by the need to ensure the delivery time and the acceptable value of the equivalent error probability. In order to guarantee the delivery of messages, the reliability of the transmitted data is controlled, which is realized by using noise-immune encoding in detection or error correction modes with verification at each of the intermediate switching nodes or directly by the recipient. Thus, to study the probability-time characteristics of data exchange control methods in data exchange networks, it is necessary to analyze the process of packet transmission in the specified modes, taking into account the effect of intermediate switching nodes. In this case, in general, one should take into account both the presence of several data streams from other sources, and the possibility of failures in service at each of the switching nodes. The article describes a mathematical model of data transmission in the receiver error detection mode that allows to investigate the main probabilistic and temporal characteristics of the data transmission process in the networks of automated air traffic control systems in the mode of error detection taking into account additional information flows from other sources and possible failures at the switching nodes.

Keywords: data exchange networks, data transmission, data packets, probability-time characteristics, switching node, error correction, probability-time graph.

\section{References}

1. Alekseev S.V., Prozorov A.M., Kovalenko D.A. Fragmentation of packets in the bit oriented data transfer procedure with acknowledgment. Radio-electronic and computer systems. 2005, No. 2(10), P. 11-18. 2. Oberemok S.O. The model of the package parcels in commuting schools with the same topology of ACS network by air traffic. Navigation and communication control systems, 2018, No. 1, P. 28-31. 3. Oberemok S.O. Mathematical model of switching process in means with fully connected topology in ACS networks by air movement. Navigation and communication control systems. 2018, No. 2(48). P. 30-34. 4. Alekseev S.V. Mathematical model of the process of data transmission through intermediate message switching centers for the case of applying noise-immune code in the mode of error detection with packet checking by the recipient. Sb. sciences HUPS,
2010,No.3(25),P.123-125. 5. Bertsekas D. Gallagher R. Data networks. M., 1989, 544p. 6. Zaichenko Yu.P., Gonta Yu.V. Structural optimization of computer networks. K., 2006. 168 p. 7. Berezko M.P., Vishnevsky V.M., Levner E.V., Fedotov E.V. Mathematical models for the investigation of routing algorithms in data transmission networks. Information Processes. 2011, T.1, No. 2. P.103125. 8. Kharitonov O.A. Quality of service and efficient use of resources in multiservice networks. Vestnik Svyazi. 2014, No.12,P.48-55. 9. Popovsky V.V. Mathematical modeling of complex systems. Military Academy of Communications, $1990,156 \mathrm{p}$. 10. Shvartsman V.O. Thequality of services of networks of the next generation. Electrosvyaz. 2016, No. 3. P. 26-31. 